\title{
Culture in vitro de la renoncule des fleuristes (Ranunculus asiaticus L) \\ I. Néoformation et multiplication végétative in vitro de plantes à partir de tronçons de thalamus
}

\author{
J Meynet *, A Duclos \\ INRA, Station d'amélioration des plantes florales, La Gaudine, Fréjus, 83370 Saint-Aygulf, France
}

(Reçu le 5 septembre 1989 ; accepté le 4 janvier 1990)

\begin{abstract}
Résumé - La base du réceptacle femelle (thalamus) peut donner lieu à des néoformations de plantes qui ont été multipliées ou enracinées in vitro. Les conditions physico-chimiques de culture sont décrites; nous soulignons en particulier la stimulation du processus d'organogenèse par le 2,4-D et l'inhibition de la rhizogenèse par la glutamine et le glycocolle. Provenant de clones généralement infectés par plusieurs virus dont le virus de la mosaïque du concombre, les plantes obtenues à partir de thalamus peuvent être saines ou recèlent parfois la présence d'un potyvirus, mais le CMV a été éliminé. Elles sont conformes aux phénotypes d'origine.
\end{abstract}

Ranunculus asiaticus / néoformation / propagation / enracinement / multiplication conforme

Summary - In vitro culture of Persian buttercup (Ranunculus asiaticus L). I. Neoformation and micropropagation of plants from stumps of thalamus. The cold, darkness and 4 combinations of growth regulators were tested to induce in vitro neoformation of plants from several organs. The plants obtained were multiplied and rooted in physicochemical conditions of in vitro culture which are described (table l): particularly the organogenesis is stimulated by 2,4-D, and rooting is inhibited by glutamin and glycin (tables II and III). This method allowed us to establish in vitro culture in 27 out of the 34 different genotypes observed. Obtained from clones generally infected by several viruses, the plants neoformed through thalamus in vitro culture were either healthy or occasionally had a potyvirus (table IV), but the cucumber mosaic virus was eliminated. They were identical to the original phenotypes.

Ranunculus asiaticus / neoformation / propagation / rooting / true to type multiplication

\section{INTRODUCTION}

La renoncule des fleuristes ou renoncule des jardins (Ranunculus asiaticus $L$ ) est une espèce florale bien adaptée au climat méditerranéen et sa culture connaît aujourd'hui un regain d'intérêt. Cette espèce est très sensible à plusieurs viroses (Devergne et al, 1969 ; Ragozzino, 1972 ; Elliot et al, 1988) et à des champignons transmis par ses racines tubérisées appelées "griffes" (Ponchet et al, 1969 ; Gullino et Garibaldi, 1984). Pour ces raisons, la diffusion de variétés clones par éclats de griffes est très risquée et difficile. Aussi avons-nous choisi comme stratégie de sélection la création de variétés hybrides de clones (Meynet, 1984). Cette démarche nécessite une bonne maîtrise de la multiplication végétative pour disposer de clones parentaux en effectifs suffisants (quelques centaines de plantes) et en bon état sanitaire compatibles avec les exigences d'une production grainière industrielle. Plusieurs auteurs ont cherché à mettre au point une méthode de culture in vitro, notamment par culture d'apex végétatif (Maïa et al, 1973 ; Lercari et al, 1984) ; les contaminations bactériennes presque systématiques rendent cette méthode très aléatoire et exigent des effectifs de plantes importants. Nous avons essayé de mettre en culture des organes aériens, dans l'espoir qu'ils soient moins contaminés. Comme la

\footnotetext{
* Correspondance et tirés à part
} 
renoncule est une plante en rosette, ces organes apparaissent nécessairement après l'induction florale. Nous avons donc exploré les capacités morphogénétiques des différentes pièces florales en formation. Sachant, par ailleurs, que les tissus floraux expriment chez de nombreuses espèces une bonne aptitude à l'organogenèse (Margara, 1982), nous avons traité en particulier dans cette première partie de l'utilisation du réceptacle femelle, le thalamus.

\section{MATÉRIEL ET MÉTHODE}

\section{Matériel végétal}

L'expérimentation porte essentiellement sur des clones parentaux d'hybrides commerciaux. Sélectionnés dans des familles consanguines ( 2 à 6 générations de croisements frère $x$ sœur), ils sont souvent peu vigoureux et se multiplient faiblement. Après 5 à 8 années de culture en serre et de division de griffes, les effectifs varient de 25 à quelques centaines de plantes ; la plupart de celles-ci sont, d'autre part, infectées par le virus de la mosaïque du concombre (CMV) qui a été détecté spécifiquement par le test Elisa.

Ces clones sont implantés en octobre dans une serre maintenue à une température minimale de $+4{ }^{\circ} \mathrm{C}$, ils fleurissent de façon continue de mi-janvier à début mai de sorte que des boutons floraux sont disponibles pendant une grande partie de l'hiver.

Pour des essais préliminaires nous avons utilisé des plantes provenant de semis in vitro d'une variété hybride relativement homogène "Friandine 2059". Outre sa facilité d'obtention, ce matériel avait l'avantage d'être a priori indemne de tout agent pathogène.

\section{Néoformations de plantes à partir d'organes floraux}

a) Dans un premier essai, 3 clones, C119-2, S118-1-47 , S22-1-15, ont été retenus. En janvier 1987, des boutons encore bien fermés ont été prélevés. lls ont été immédiatement désinfectés par passage successif dans les différents bains d'éthanol à $70^{\circ}$ pendant $30 \mathrm{~s}$, d'hypochlorite de calcium $15 \mathrm{~g} . \mathrm{l}^{-1}$ pendant $20 \mathrm{~min}$, et d'eau stérile 3 fois pendant $3 \mathrm{~min}$. Quatre organes ont été prélevés et mis en culture : la partie terminale du pédoncule coupée longitudinalement en 2 moitiés, les sépales, la base des pétales avec leur glande nectarifère, le thalamus entier portant des ovaires bien différenciés à la base et au stade de primordia au sommet.

Ces différents explants ont été répartis dans des boîtes de Petri de $55 \mathrm{~mm}$ de diamètre contenant un milieu de Murashige et Skoog (1962) dilué de moitié et complété avec Fe EDTA (EDTA = Ethylène diéthylaminetétracétique) $65 \mathrm{mg}^{-1}$, myoinositol $100 \mathrm{mg}^{-l^{-1}}$, acide nicotinique $5 \mathrm{mg}^{-1}$, thiamine. $\mathrm{HCl} 1 \mathrm{mg} . \mathrm{l}^{-1}$, pyridoxine. $\mathrm{HCl} 1 \mathrm{mg} . \mathrm{l}^{-1}$, pantothénate de calcium $1 \mathrm{mg} . \mathrm{l}^{-1}$, saccharose $20 \mathrm{~g} . l^{-1}$, gélose $8 \mathrm{~g} . \mathrm{I}^{-1}$. Le $\mathrm{pH}$ a été ajusté à 5,8 avant la stérilisation à l'autoclave à $115^{\circ} \mathrm{C}$ pendant
20 min. Quatre milieux numérotés de BI à BIV se différenciant uniquement par la nature et les équilibres en substances de croissance sont décrits dans le tableau I.

Après 6 semaines, tous les explants sains ont été transférés sur un milieu de multiplication analogue au milieu $\mathrm{B}$ l additionné de $50 \mathrm{mg}^{-1}$ de glutamine et de $50 \mathrm{mg} . \mathrm{l}^{-1}$ de glycocolle. Toute la phase de vitroculture a été réalisée dans une chambre climatisée à $18^{\circ} \mathrm{C}$ et éclairée pendant $10 \mathrm{~h}$ par des tubes fluorescents (12 W. $\mathrm{m}^{-2}$ environ).

Tableau I. Composition en substances de croissance des milieux de culture utilisés $\left(\mathrm{mg} . \mathrm{l}^{-1}\right)$.

$B I \quad B I I \quad B I I I B I V$

\begin{tabular}{llllll}
\hline Benzyladenine (BA) & 0,5 & 0,5 & 0,5 & 0,5 \\
Acide indolylacétique (AIA) & 0,5 & 0 & 0 & 0 \\
Acide 2,4-dichlorophénoxy- & & & & \\
acétique (2,4-D) & 0 & 0,1 & 0 & 0,1 \\
Acide naphtalèneacétique (ANA) & 0 & 0 & 0,5 & 0,5
\end{tabular}

b) En mars de la même année, les clones C119-2 et S118-1-4-7 ont servi de donneurs de thalamus uniquement, mais ceux-ci ont été sectionnés transversalement en 3 tronçons et mis en culture sur le seul milieu BII. Les boutons floraux ont séjourné (froid + ) ou non (froid -) à $2{ }^{\circ} \mathrm{C}$ pendant $7 \mathrm{j}$ avant leur mise en culture.

Les explants sont maintenus (obscurité + ) ou non (obscurité -) à l'obscurité à $18^{\circ} \mathrm{C}$, pendant 6 semaines, ils sont ensuite transférés sur un milieu neuf BII pour 4 semaines puis sur le milieu de multiplication.

c) Pendant les mois de février et mars 1988, 34 génotypes non apparentés ont fait l'objet d'un essai de mise en culture in vitro selon une procédure unique : les boutons ont été prétraités à $2^{\circ} \mathrm{C}$ pendant $7 \mathrm{j}$, 3 tronçons de thalamus par bouton ont été placés sur milieu Bll pendant 6 semaines à l'obscurité puis 4 semaines sous un éclairement de $10 \mathrm{~h}$ de jour.

\section{Multiplication et enracinement in vitro}

Depuis 1984, de nombreux essais préliminaires ont été réalisés avec des plantes provenant de semis in vitro pour améliorer les techniques de Maïa et al (1973) qui visaient essentiellement à assainir le clone virosé «Barbaroux» par culture in vitro du méristème apical. Différentes combinaisons de substances de croissance, plusieurs équilibres de macro-éléments, plusieurs concentrations de saccharose... ont été essayés et ont contribué à la mise au point des milieux de multiplication et d'enracinement aujourd'hui employés. Nous ne décrirons ici qu'un essai portant sur l'adjonction au milieu $\mathrm{BI}$ de 3 acides aminés, le glycocolle, la glutamine et l'acide aspartique. Ces acides aminés ont été utilisés à la dose de $200 \mathrm{mg}^{-1}$ et toutes les combinaisons présence/absence ont été testées. Vingt plantules par traitement élémentaire ont fait l'objet de notations : taux de multiplication, élongation foliaire, enracinement après 18 et $30 \mathrm{j}$. 


\section{Transfert en conditions horticoles et modalités de culture des plantes obtenues}

Les plantes néoformées à partir de thalamus, multipliées et enracinées in vitro, ont été transférées sur un terreau horticole de façon échelonnée d'octobre à décembre, elles ont été élevées pendant 3 semaines dans une chambre climatisée à $18^{\circ} \mathrm{C}$ éclairée $12 \mathrm{~h}$ avec des lampes à vapeur de sodium (environ 100 $\mathrm{W} \cdot \mathrm{m}^{-2}$ ), puis implantées dans une serre maintenue à une température supérieure à $4^{\circ} \mathrm{C}$. L'épanouissement des premières fleurs à été observé au début de février pour les plantes sorties de tubes en octobre et à la mimars pour celles sorties en décembre.

\section{Observation en serre du matériel obtenu}

L'état sanitaire des plantes cultivées en serre a été noté selon des indices visuels (présence de mosaïque sur feuilles, de panachure sur fleur ou autres symptômes); des tests Elisa révélateurs de CMV, des indexages sur tabac et chénopode et des observations en microscopie électronique ont été pratiqués, en utilisant des feuilles juvéniles prélevées juste avant l'initiation du premier bouton floral, par A Berling (GRISPAntibes).

La conformité au clone de départ a été jugée notamment sur des caractéristiques florales : ramification de la hampe, morphologie du bouton et des pétales, duplicature, coloris de la fleur épanouie...

Enfin le grossissement des griffes et les capacités de reproduction par graines du matériel obtenu ont été appréciés.

\section{RÉSULTATS ET DISCUSSION}

\section{Néoformations de plantes}

\section{Influence du type d'organe et du milieu de culture}

Les pétales se sont allongés, ont verdi puis se sont nécrosés et sont morts sans donner de néoformation (sauf une exception sur le milieu BIV).
Les sépales et les pédoncules floraux n'ont pratiquement pas évolué. En revanche les thalamus ont donné des résultats positifs qui sont rapportés dans le tableau II.

Seuls les milieux BIl et BIV ont permis d'obtenir des plantes cultivables en serre. Le fait que ces 2 milieux contiennent du 2,4-D souligne l'importance de cette substance pour la néoformation de plantes à partir de thalamus. Toutes les néoformations obtenues provenaient de carpelles bien structurés de la base du réceptacle femelle.

Quelques bourgeons végétatifs bien organisés et individualisés ont pu apparaître directement à la surface de l'explant selon un processus morphogénique comparable à celui observé sur des capitules de gerbera par exemple (Pierik et al, 1973). Mais, le plus souvent, les premières manifestations de l'organogenèse s'expriment sous forme de feuilles gaufrées et recroquevillées (fig 1). Après un ou plusieurs repiquages sur le milieu de multiplication, une plantule ou de petites touffes se différencient à partir des tissus sous-épidermiques de la formation foliacée initiale. Ce phénomène paraît être stimulé par le

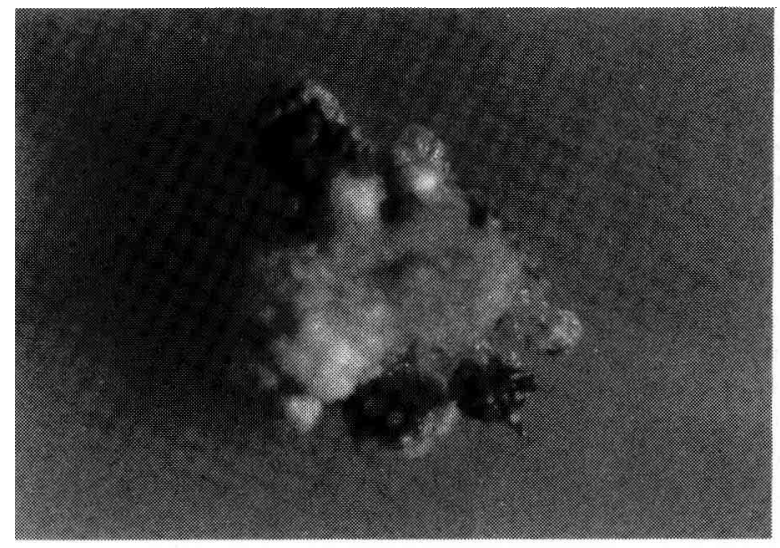

Fig 1. Néoformation de bourgeons observée sur tronçon basal de thalamus cultive in vitro.

Tableau II. Influence du milieu de culture et du clone de départ sur la fréquence des néoformations observées sur thalamus. $M C=$ nombre de thalamus mis en culture ; $S:$ nombre de thalamus non contaminés ; PI : nombre de thalamus ayant donné au moins une plante observée en serre.
$B I$
$B / I$
BIII
$B I V$

\begin{tabular}{|c|c|c|c|c|c|c|c|c|c|c|c|c|}
\hline & MC & $\mathrm{S}$ & $\mathrm{Pl}$ & MC & $\mathrm{S}$ & $\mathrm{Pl}$ & MC & $\mathrm{S}$ & $\mathrm{PI}$ & MC & $\mathrm{S}$ & $\mathrm{Pl}$ \\
\hline C 119-2 & 8 & 3 & 0 & 8 & 3 & 2 & 8 & 2 & 0 & 8 & 2 & 1 \\
\hline S 118-1-4-7 & 8 & 3 & 0 & 8 & 2 & 1 & 8 & 3 & 0 & 8 & 4 & 1 \\
\hline S 22-1-15 & 8 & 1 & 0 & 8 & 2 & 1 & 8 & 1 & 0 & 8 & 2 & 0 \\
\hline Total & 24 & 7 & 0 & 24 & 7 & 4 & 24 & 6 & 0 & 24 & 8 & 2 \\
\hline
\end{tabular}


2,4-D. En effet, il a pu être reproduit après un transfert, pour une durée de 4 semaines sur un milieu Bll, de plantes provenant de plusieurs cycles de multiplication par bourgeonnement axillaire et présentant à l'origine des feuilles «normales".

Le taux de contamination bactérienne (71\% sur l'ensemble des essais réalisés) est élevé mais non rédhibitoire dans la mesure où chaque plante issue de griffe peut fournir 5 à 25 boutons floraux, et cette technique ne compromet pas la survie des plantes mères.

\section{Effets d'un prétraitement par le froid et d'une culture à l'obscurité}

Les facteurs physiques testés n'ont pas d'effets sur les différents paramètres observés : la fré- quence des néoformations (tableau III), la vitesse d'apparition de plantules différenciées et le taux de contamination bactérienne.

Sur les 22 plantes ainsi obtenues, 18 proviennent du tronçon basal, 4 du tronçon médian, aucune de la zone apicale.

\section{Influence du facteur génotypique}

Les contaminations bactériennes ont été très fréquentes; presque toujours, les 3 tronçons d'un même bouton étaient affectés simultanément; cependant, dans 2 cas, le tronçon basal restait sain et même apte à régénérer une plante alors que le tronçon apical était contaminé. Le tableau IV indique que, sur 407 prélèvements, 128 présentent au moins 1 tronçon de thalamus apparemment sain après 3 repiquages, soit un

Tableau III. Effets d'une culture à l'obscurité et d'un prétraitement par le froid sur la fréquence des néoformations observées sur thalamus. $\mathrm{N} 1$ = nombre de thalamus ayant donné au moins 1 plante après 1 repiquage sur milieu de multiplication tous génotypes confondus; $\mathrm{N} 2=$ après 2 repiquages ; N3 = après 3 repiquages; N4: après 4 repiquages.

\begin{tabular}{|c|c|c|c|c|c|c|c|c|c|c|c|c|}
\hline & $M C$ & $\begin{array}{l}\text { Froid + } \\
S\end{array}$ & $P I$ & $M C$ & $\begin{array}{c}\text { Froid- } \\
S\end{array}$ & $P I$ & $M C$ & $\underset{S}{\text { Froid }+}$ & $P I$ & $\begin{array}{l}\dot{e}- \\
M C\end{array}$ & $\begin{array}{l}\text { Froid - } \\
S\end{array}$ & $P I$ \\
\hline $\begin{array}{l}\text { C } 119-2 \\
\text { S } 118-1-4-7 \\
\text { N1 } \\
\text { N2 } \\
\text { N3 } \\
\text { N4 }\end{array}$ & $\begin{array}{l}12 \\
12\end{array}$ & $\begin{array}{l}5 \\
5\end{array}$ & $\begin{array}{l}5 \\
3 \\
4 \\
8 \\
- \\
-\end{array}$ & $\begin{array}{l}12 \\
12\end{array}$ & $\begin{array}{l}4 \\
4\end{array}$ & $\begin{array}{l}3 \\
2 \\
1 \\
4 \\
5 \\
-\end{array}$ & $\begin{array}{l}12 \\
12\end{array}$ & $\begin{array}{l}5 \\
7\end{array}$ & $\begin{array}{l}3 \\
2 \\
0 \\
2 \\
4 \\
5\end{array}$ & $\begin{array}{l}12 \\
12\end{array}$ & $\begin{array}{l}3 \\
5\end{array}$ & $\begin{array}{l}3 \\
1 \\
0 \\
2 \\
4 \\
-\end{array}$ \\
\hline
\end{tabular}

Tableau IV. Influence du génotype sur la fréquence des néoformations observées sur thalamus, l'état sanitaire et la conformité phénotypique des plantes obtenues. Viroses : - = sans symptômes ; $X=$ symptômes de mosaïque/feuilles ; $\mathrm{X}-=$ certains sous-clones présentent des symptômes, d'autres aucun ; ? = douteux.

\begin{tabular}{|c|c|c|c|c|c|c|c|c|c|c|c|}
\hline $\begin{array}{l}\text { Code } \\
\text { génotype }\end{array}$ & $M C$ & $S$ & $P I$ & Virose & Conformité & $\begin{array}{l}\text { Code } \\
\text { génotype }\end{array}$ & $M C$ & $S$ & $P I$ & Virose & Conformité \\
\hline $\mathrm{R} 2$ & 7 & 2 & 1 & $x$ & $x$ & R22 & 18 & 2 & 1 & - & $x$ \\
\hline $\mathrm{R} 4$ & 8 & 0 & 0 & & & R23 & 14 & 3 & 3 & $?-$ & $x$ \\
\hline R5 & 11 & 0 & 0 & & & R24 & 18 & 7 & 5 & $?$ & $x$ \\
\hline $\mathrm{R} 8$ & 12 & 10 & 7 & - & $x$ & R25 & 8 & 2 & 2 & $x-$ & $x$ \\
\hline $\mathrm{R} 9$ & 15 & 10 & 9 & - & $x$ & $\mathrm{R} 26$ & 9 & 1 & 0 & & \\
\hline $\mathrm{R} 10$ & 8 & 4 & 0 & & & $\mathrm{R} 27$ & 13 & 2 & 1 & & \\
\hline R11 & 18 & 14 & 9 & - & $x$ & R28 & 2 & 0 & 0 & & \\
\hline $\mathrm{R} 12$ & 18 & 6 & 6 & $x-$ & $x$ & R29 & 7 & 3 & 1 & - & $x$ \\
\hline $\mathrm{R} 13$ & 14 & 6 & 4 & $x$ & $x$ & R30 & 8 & 2 & 1 & & \\
\hline $\mathrm{R} 14$ & 15 & 3 & 2 & $x-$ & $x$ & R31 & 14 & 3 & 0 & & \\
\hline $\mathrm{R} 15$ & 16 & 4 & 2 & - & $x$ & R32 & 12 & 2 & 0 & & \\
\hline R16 & 14 & 3 & 1 & $?$ & $x$ & R33 & 7 & 3 & 2 & - & $x$ \\
\hline R17 & 8 & 3 & 1 & - & $x$ & R34 & 5 & 1 & 1 & & \\
\hline $\mathrm{R} 18$ & 10 & 5 & 4 & - & $x$ & R35 & 10 & 1 & 0 & & \\
\hline R19 & 14 & 6 & 5 & - & $x$ & R36 & 12 & 2 & 1 & & \\
\hline R20 & 19 & 3 & 1 & $?$ & $x$ & R40 & 8 & 2 & 1 & $x$ & $x$ \\
\hline $\mathrm{R} 21$ & 18 & 10 & 8 & - & $x$ & $\mathrm{Ba}$ & 17 & 3 & 3 & - & $?$ \\
\hline Total & & & & & & 34 & 407 & 128 & 82 & & \\
\hline
\end{tabular}


taux de contamination moyen de $68 \%$ des explants mis en culture. Toutefois, ce taux semble varier beaucoup selon les génotypes (de 2/12 pour $R 8$ à 11/11 pour $R 5$ ).

La base du thalamus est très favorable à l'organogenèse, puisque $64 \%$ des tronçons basaux non contaminés régénèrent au moins 1 plante. Vingt-sept génotypes sur les 34 testés ont pu être ainsi mis en culture in vitro. Dans l'état actuel de ce travail, compte tenu des effectifs observés, rien ne nous permet d'affirmer que les 7 clones restants sont rebelles à ce procédé de régénération et, dès à présent, nous pouvons estimer que la méthode de néoformation de plantes par culture de tronçons basaux de thalamus est applicable à une gamme très large de renoncules.

\section{Multiplication et enracinement}

Les plantules isolées ou associées en touffes s'enracinent facilement sur presque tous les milieux expérimentés, même s'ils contiennent une cytokinine. D'autre part, les plantules découpées et transférées sur tous les milieux dépourvus de 2,4-D se multiplient par bourgeonnement axillaire. Dans ces conditions générales, les résultats du tableau $V$ doivent être soulignés: certains acides aminés ont un effet déterminant sur la croissance in vitro, en particulier la rhizogenèse. La glutamine et le glycocolle inhibent l'enracinement, en revanche l'acide aspartique favorise l'élongation foliaire, la croissance et la tubérisation des racines. La relation entre le métabolisme azoté et le fonctionnement racinaire paraît évidente chez cette espèce.

Le milieu qui s'est révélé le plus favorable à la multiplication par bourgeonnement axillaire est un milieu analogue à $\mathrm{Bl}$ enrichi de $50 \mathrm{mg} / \mathrm{l}$ de glutamine, $50 \mathrm{mg} / \mathrm{l}$ de glycocolle et de $30 \mathrm{~g} / \mathrm{l}$ de saccharose. Pour l'enracinement et l'assurance d'un bon transfert en conditions horticoles, c'est le milieu de Tulecke (1963) (caractérisé notamment par une teneur très faible en ion ammonium) dilué de moitié, dépourvu d'acides aminés et de substances de croissance, qui s'est avéré le meilleur.

\section{Observation en serre du matériel obtenu}

Alors que de nombreuses plantes dans la plupart des clones de départ utilisés étaient infectées par le virus de la mosaïque du concombre, ce virus n'a été retrouvé dans aucune des jeunes plantes analysées par le test Elisa. Ce résultat demande à être confirmé en affinant les observations virologiques au niveau :

- des plantes mères. La répartition virale en leur sein peut être hétérogène : elles pourraient présenter soit des secteurs sains, comme l'ont observé Lecoq et al (1982) sur piment, et engendrer, après éclats de griffes, des populations partiellement saines, soit des gradients de concentration avec des teneurs nulles ou très faibles de particules virales au niveau du thalamus au moment du prélèvement ;

- des plantes issues de culture in vitro. Le test pratiqué sur des jeunes plantes avant l'initiation florale n'a peut-être pas permis de détecter le CMV si sa teneur initiale était très faible (Digat, 1982). Il sera donc refait sur ce même matériel après sa tubérisation.

Par ailleurs, bien qu'elles soient indemnes de CMV, certaines plantes régénérées présentent des symptômes de mosaïque sur feuilles qui peuvent être très sévères (tableau IV). Les indexages de ces plantes réalisés sur tabac et chénopode se sont avérés négatifs. Cependant

Tableau V. Effets de 3 acides aminés sur le taux de multiplication et le développement in vitro des renoncules. Multiplication : $X=$ taux $<1,5 ; X X=1,5<$ taux $<2,5 ; X X X=$ taux $>2,5$. Élongation foliaire : $X=L<1,5 \mathrm{~cm} ; X X=1,5$ $<L<2,5 \mathrm{~cm} ; X X X=L>2,5 \mathrm{~cm}$. Enracinement : nombre d'explants enracinés sur 20 observés. * Certaines racines étaient tubérisées.

\begin{tabular}{lrrrrrrrr}
\hline Glycocolle mg/l & 0 & 200 & 0 & 0 & 200 & 200 & 0 & 200 \\
Glutamine mg/l & 0 & 0 & 200 & 0 & 200 & 0 & 200 & 200 \\
Ac aspartique mg/l & 0 & 0 & 0 & 200 & 0 & 200 & 200 & 200 \\
Multiplication & $X X$ & $X X$ & $X X$ & $X$ & $X X$ & $X$ & $X$ & $X X X$ \\
Élongation foliaire & $X$ & $X$ & $X$ & $X X X$ & $X$ & $X$ & $X$ & $X X$ \\
Enracinement après 18 j & 9 & 1 & 0 & 9 & 0 & 0 & 2 & 0 \\
Enracinement après 30j & 19 & 9 & 8 & $20^{*}$ & 3 & 11 & 11 & 5 \\
\hline
\end{tabular}


des observations en microscopie électronique ont révélé la présence d'un virus flexueux qui pourrait correspondre au virus de la renoncule (RV) décrit par Elliot et al (1988) et transmissible, selon ces mêmes auteurs, seulement sur le piedd'alouette (Delphinium consolida) parmi une large gamme d'hôtes testés. Les symptômes de mosaïque sont parfois exacerbés sur les plantes issues d'in vitro par rapport au matériel de départ. Ce fait pourrait indiquer que ce virus, à la faveur de la multiplication in vitro, se trouve davantage concentré dans les plantes ou qu'une co-infection (avec le CMV ou des bactéries) atténue son expression.

\section{Conformité phénotypique}

Avec les marqueurs disponibles (essentiellement des caractéristiques florales), toutes les plantes régénérées sont phénotypiquement conformes à leurs plantes mères. Seul le clone "Barbaroux" (Ba) paraît avoir une descendance douteuse ; en effet certaines hampes portant les premières fleurs sont quelquefois fasciées, cette fasciation sporadique est apparue dans chacun des 3 sousclones.

Par rapport au matériel d'origine multiplié par éclats de griffes, le nombre de graines produites par les plantes obtenues après multiplication in vitro est supérieur, les griffes produites sont plus grosses et se multiplient davantage.

Ces meilleures performances agronomiques pourraient être l'expression d'une restauration de l'état sanitaire.

\section{CONCLUSION}

La néoformation de plantes à partir de tronçons basaux de thalamus chez la renoncule des fleuristes est possible sur des clones parentaux de variétés hybrides même si ces clones sont représentés par de très faibles effectifs, virosés et contaminés par des bactéries endogènes.

Quelques plantes, dont l'état sanitaire et les performances agronomiques ont été restaurés, ont été obtenues. Leur conformité phénotypique à leur plante mère permet d'espérer une conformité de leurs descendances sexuées aux hybrides de clones actuellement commercialisés.

D'autres plantes s'avèrent être infectées par un virus flexueux qui se manifeste par des symptômes très sévères de mosaïque foliaire. L'éradication de ce virus par culture in vitro du méristème apical peut désormais être tentée dans la mesure où les effectifs de matériel de départ ne sont plus limitatifs, la multiplication in vitro restant efficace malgré la contamination virale.
Enfin, au cours de la mise au point des méthodes de multiplication in vitro, d'importantes différences variétales ont été relevées; cette variabilité des réponses génotypiques, relative notamment au taux de prolifération, permet d'envisager la possibilité de diffuser des variétés clones.

\section{REMERCIEMENTS}

Nous remercions A Berling du GRISP (Groupement Régional d'intérêt scientifique phytosanitaire) d'Antibes qui a assuré, toutes les analyses et études virales et E Berthelé qui a contribué aux observations en serre.

\section{RÉFÉRENCES}

Devergne JC, Cardin L, Marais A (1969) Isolement de quelques virus infectant la renoncule cultivée, Ranunculus asiaticus $\mathrm{L}$, dans le Sud-Est de la France. Ann Phytopathol 1 hors-série, 321-328

Digat B (1982) Elimination de virus par culture de méristèmes. In: La culture in vitro et ses applications horticoles. Technique et Documentation Lavoisier, Paris, $126 \mathrm{pp}$

Elliot MS, Zettler FW, Gallegati M, Ko NJ (1988) A potyvirus infecting Ranunculus asiaticus. Acta Hortic The Hague 234, 39-43

Gullino ML, Garibaldi A (1984) Le principali malattie fungine del ranuncolo. Colture Protette 10, 76-78

Lecoq $H$, Pochar E, Pitrat M, Laterrot H, Marchoux $G$ (1982) Identification et exploitation des résistances aux virus chez les plantes maraîchères. Cryptogam Mycol 3, 333-345

Lercari G, Accati Garibaldi E, Littardi M (1984) Primi risultati sullimpiego della coltura in vitro del ranuncolo. Colture protette 10,73-75

Maia E, Bettachini B, Beck D, Marais A (1973) Régénération de renoncules par culture d'apex in vitro. Ann Phytopathol 5, 2, 125-129

Margara J (1982) Réversion vers l'état végétatif d'apex inflorescentiels. In: Bases de la multiplication végétative. Les méristèmes et l'organogenèse. INRA, 103, 165-174

Meynet $J$ (1984) Propagazione e selezione del ranuncolo. Colture Protette 10, 61-68

Murashige T, Skoog F (1962) A revised medium for rapid growth and bio-assays with tobacco tissue culture. Phys Plantarum 15, 473-497

Pierik RLM, Steegmans HHM, Marelis JJ (1973) Gerbera plantlets from in vitro cultivated capitulum explants. Sci Hortic Amst 1, 117-119

Ponchet J, Mercier S, Augé G (1969) Une maladie nouvelle de la renoncule cultivée. Ann Phytopathol 1 hors-série, 203-207

Ragozzino A (1972) Due malattie de virus del ranuncolo in Campania. Riv Ortoflorofrutticoltura ltal 56 157-161

Tulecke WC (1963) Cell proliferation from pollen of Torreya nucifera. Contrib Boyce Thomson Inst 22 , 153-163 